\title{
REVIEWS
}

\section{Stress-related mucosal disease in the critically ill patient}

\author{
Marc Bardou, Jean-Pierre Quenot and Alan Barkun
}

\begin{abstract}
Bleeding from stress-related mucosal disease in critically ill patients remains an important clinical management issue. Although only a small proportion (1-6\%) of patients admitted to an intensive care unit (ICU) will bleed, a substantial proportion exhibit clinical risk factors (mechanical ventilation for $>48 \mathrm{~h}$ and a coagulopathy) that predict an increased risk of bleeding. Furthermore, upper gastrointestinal mucosal lesions can be found in $75-100 \%$ of patients in ICUs. Although uncommon, stress-ulcer bleeding is a severe complication with an estimated mortality of $40-50 \%$, mostly from decompensating an underlying condition or multiorgan failure. Although the vast majority of patients in ICUs receive stress-ulcer prophylaxis, largely with PPIs, some controversy surrounds their efficacy and safety. Indeed, no single trial has shown that stress-ulcer prophylaxis reduces mortality. Some reports suggest that the use of PPIs increases the risk of nosocomial infections. However, several meta-analyses and cost-effectiveness studies suggest PPIs to be more clinically effective and cost-effective than histamine-2 receptor antagonists, without considerable increases in nosocomial pneumonia. To help clinicians use the most appropriate strategy for treatment of patients in the ICU, this Review presents the latest information on all aspects of stress-related mucosal disease.
\end{abstract}

Bardou, M. et al. Nat. Rev. Gastroenterol. Hepatol. 12, 98-107 (2015); published online 6 January 2015; doi:10.1038/nrgastro.2014.235

\section{Introduction}

Critically ill patients are at risk of bleeding from stressrelated mucosal disease (SRMD), ${ }^{1}$ which is an important clinical problem. ${ }^{2,3}$ Patients who experience SRMD have a prolonged stay in intensive care and an increased risk of mortality. ${ }^{4-6}$ Even though the true incidence is debated, only a small proportion of critically ill patients will actually bleed. ${ }^{7.8}$ For example, a cohort study conducted in Germany and published in 2014 found a bleeding rate of $0.9 \% .{ }^{6}$ Nevertheless, the clinical factors that predict a higher risk of bleeding are increasingly found among patients admitted to an intensive care unit (ICU). , $, 7,8^{2}$ Stress-ulcer prophylaxis (SUP) has been found to be efficacious and is thus considered as a standard of care in the ICU, included in the mnemonic FASTHUG (Feeding, Analgesia, Sedation, Thromboembolic prophylaxis, Head of bed elevation, stress Ulcer prophylaxis, Glucose control) that was developed by ICU physicians to ensure that key aspects of care are addressed during each patient encounter. ${ }^{9}$ Histamine-2 receptor antagonists (H2RAs) have been found to be efficacious in preventing SRMD bleeding in the ICU setting, as have PPIs. ${ }^{3,78,10}$ Their comparative efficacies, the possible development of nosocomial pneumonia and cost-effectiveness remain subjects of controversy, with disparate data in the literature. ${ }^{10-12}$ Therefore, uncertainty over whether routine SUP is indicated in critically ill patients still exists among clinicians in 2014. In this Review, the latest information on all aspects of SRMD are provided as an overview.

Competing interests

The authors declare no competing interests.

\section{Epidemiology of stress-ulcer bleeding}

Endoscopies performed within $72 \mathrm{~h}$ of the onset of illness have shown that $75-100 \%$ of critically ill patients exhibit gross gastric lesions. ${ }^{13}$ Lesions are most often diffuse subepithelial haemorrhages and erosions; however, if massive bleeding occurs it suggests that an ulcer has developed. ${ }^{2}$

Many definitions of stress-ulcer bleeding have been put forward since it was first described in $1969 .{ }^{14}$ Although occult bleeding, as defined by guaiac stool positivity in samples from nasogastric tube or emesis, has been proposed as a working definition of stress-ulcer bleeding, the more relevant clinical presentation is that of overt bleeding manifesting as haematemesis, coffee ground emesis, melena, or bloody nasogastric aspirate. Pooled results from 10 randomized trials of prophylactic therapy (versus placebo or no therapy) performed from 1980 to 1998 suggested an incidence of $17 \%$ for stress-ulcer bleeding. ${ }^{2}$ However, in reports from the past 10 years, the incidence of SRMD-associated clinically significant bleeding or stress-ulcer bleeding (variably defined to include overt bleeding combined with transfusion, haemodynamic instability and/or the need for intervention) has markedly decreased. Indeed, from a pooled estimate of $8 \%$ in older randomized trials, ${ }^{2}$ with the advent of improved care of critically ill patients, appropriate prophylactic therapy and increasing use of enteral feedings, $1,7,15,16$ the reported pooled incidence in what are principally trials, published between 1993 and 2010, or retrospective analyses spanning over the same time frame, is now $<1 \%,{ }^{6,17,18}$ Nonetheless, SRMD and clinically significant bleeding remain important clinical problems as the associated mortality is high, related primarily to the patients' underlying illness. 


\section{Key points}

- Prevalence of clinically important stress-ulcer bleeding is low ( 1\%), but because of its severity it remains an important issue

- Prophylaxis for stress-ulcer bleeding should be restricted to patients with acknowledged risk factors because of the risk of nosocomial infection

- Despite controversies, PPIs seem to be the most clinically effective and cost-effective strategy

- Randomized clinical trials and observational studies are needed to assess new preventive strategies and to adapt therapeutic management approaches of upper gastrointestinal bleeding to the intensive care unit setting

- Stress-ulcer prophylaxis is being overused; two-thirds of patients without riskfactors receive treatment, two-thirds continue treatment upon transfer from the intensive care unit and one-third are discharged home on treatment without a new indication production of prostaglandins, mucin glycoproteins, water, bicarbonates, trefoil factor family peptides, phospholipids and heat-shock proteins (HSPs), particularly HSP70. ${ }^{28-31}$ Prostaglandins stimulate mucosal blood flow, and mucus and bicarbonate production, thereby enhancing epithelial cell growth and repair. ${ }^{32}$ The mucous bicarbonate barrier forms a physical barrier against the influx of luminal acid and pepsin, and is also important in trapping bicarbonate anions that have diffused from the gastric epithelial cells. ${ }^{22}$ Bicarbonate is powerful enough to neutralize the $\mathrm{pH}$ within the mucus gel on the epithelial cell surface despite a luminal $\mathrm{pH}$ of 1.5-2.0. ${ }^{33,34}$ Gastric epithelial cell restitution (or reepithelization) is a defensive mechanism whereby rapid, energy-dependent migration of epithelial cells occurs towards areas of superficial damage, leading to the restoration of epithelial integrity. ${ }^{22}$ Oxygen free-radical formation $^{35}$ and physiological stress ${ }^{36}$ have been implicated in reducing the rate of cellular proliferation and gastric epithelial restitution.

Among the aggressive physiological factors that might act to break down the mucosal protective defences, splanchnic hypoperfusion (or gastric mucosal ischaemia) is thought to be the major underlying cause of SRMD in critically ill patients. ${ }^{37}$ The shunt of blood away from the viscera and skin is an adaptation to stress that aims to preserve perfusion to the vital organs during an insult. Temporary shunting of visceral blood flow is well tolerated; however, it becomes maladaptive, as it results in lesions, when prolonged. MacLaren and colleagues ${ }^{38}$ showed that shock or hypotension is associated with a small but significant increased risk of gastrointestinal haemorrhage (OR, 1.17; 95\% CI 1.04-1.33) whereas hypertension seems to be protective (OR, 0.77; 95\% CI 0.67-0.87). Gastric mucosal perfusion decreases early during critical illness ${ }^{39,40}$ owing to a number of factors: activation of the sympathetic nervous system; increased catecholamine release and vasoconstriction, notably within the gastrointestinal tract; hypovolaemia; decreased cardiac output; release of proinflammatory cytokines; ${ }^{41-44}$ and impaired production of nitric oxide. ${ }^{35,45}$ Decreased microcirculation in the gastrointestinal tract is even more likely to be observed in patients with sepsis, ${ }^{39}$ even if sepsis is not unanimously described as an independent risk factor for SRMD. ${ }^{4,38}$ As a consequence of splanchnic hypoperfusion gastrointestinal motility is decreased, ${ }^{46}$ delaying the removal of acidic material and other irritants from the stomach, prolonging exposure to gastric acid and resulting in a corresponding increase in the risk of ulceration..$^{37,43,44}$

The factors favouring gastroduodenal mucosal damage in patients in the ICU are a decrease in the washout effect ${ }^{47}$ leading to local intramural acidosis, increased freeradical formation, ${ }^{48,49}$ decreased acid-buffering capacity, ${ }^{50}$ a decrease in mucus and bicarbonate secretion, ${ }^{49,51-53}$ and possibly a defect in epithelial cell restitution. ${ }^{54}$ The end result of these effects is an increase in $\mathrm{H}^{+}$ion backdiffusion and disruption of the epithelial barrier, ${ }^{37,47,50,55,56}$ ultimately allowing injury to the gastric mucosa. Pepsin might cause direct injury to the gastric mucosa, but 


\section{REVIEWS}

Table 1 | Risk factors for stress-ulcer bleeding from multiple regression analysis

\begin{tabular}{|c|c|c|}
\hline Reference & $\begin{array}{l}\text { Risk factor for stress related } \\
\text { mucosal damage* }\end{array}$ & $\begin{array}{l}\mathrm{OR}(95 \% \mathrm{Cl} \text { or } \\
P \text { value })\end{array}$ \\
\hline Cook et al. $(1994)^{4}$ & $\begin{array}{l}\text { Respiratory failure requiring mechanical } \\
\text { ventilation for }>48 \mathrm{~h}\end{array}$ & $15.6(P<0.001)$ \\
\hline $\begin{array}{l}\text { Laine et al. }(2008)^{3} \text {, } \\
\text { Cook et al. }(1994)^{4}\end{array}$ & $\begin{array}{l}\text { Coagulopathy (platelet count }<50,000 \\
\text { platelets per } \mathrm{ml}^{3} \text {, INR }>1.5 \text {, or } \\
\text { partial-thromboplastin time more than } \\
\text { two times the control value) }\end{array}$ & $4.3(P<0.001)$ \\
\hline Cook et al. $(1999)^{20}$ & Maximum serum creatinine level & $1.16(1.02-1.32)$ \\
\hline MacLaren et al. $(2014)^{27}$ & Acute kidney injury & $1.21(1.02-1.43)$ \\
\hline MacLaren et al. $(2014)^{27}$ & Acute respiratory failure & $1.31(1.10-1.56)^{\ddagger}$ \\
\hline MacLaren et al. (2014) $)^{27}$ & $\begin{array}{l}\text { Age }>50 \text { years ( } v s<40 \text { years) } \\
50-59 \text { years } \\
60-69 \text { years } \\
70-79 \text { years } \\
>80 \text { years }\end{array}$ & $\begin{array}{l}1.46(1.18-1.83)^{\ddagger} \\
1.66(1.26-2.19)^{\ddagger} \\
1.72(1.27-2.34)^{\ddagger} \\
2.04(1.48-2.83)^{\ddagger}\end{array}$ \\
\hline MacLaren et al. (2014) $)^{27}$ & Acute hepatic injury & $1.56(1.29-1.88)^{\ddagger}$ \\
\hline MacLaren et al. $(2014)^{27}$ & Chronic hepatic injury & $1.85(1.47-2.33)^{\ddagger}$ \\
\hline MacLaren et al. $(2014)^{27}$ & Sex: male versus female & $1.17(1.03-1.33)^{\ddagger}$ \\
\hline
\end{tabular}

*Other risk factors that were identified by simple regression analysis, but lost statistical significance after multiple regression include: hypotension; sepsis; hepatic failure; glucocorticoid administration; and anticoagulation therapy. FPropensity score odds ratio. Abbreviation: INR, international normalized ratio.

becomes inactive if the $\mathrm{pH}$ is $>4.5 .{ }^{37}$ In addition, pepsin facilitates the lysis of clots, which could enhance bleeding from SRMD. ${ }^{57,58}$

\section{Pharmacological prophylaxis of SRMD}

Initiation of SUP using acid-suppressants in the ICU setting is now established practice. Two landmark studies published in 1994 and 1999 by the Canadian Critical Care Trials Group serve as the benchmark for SUP in this context, ${ }^{4,20}$ and 1999-2010 estimates indicate that $\sim 90 \%$ of patients in ICU receive some type of SUP. ${ }^{6}$ The different approaches to prevent SRMD-related bleeding are based on the understanding of the pathophysiology and recognized risk factors described earlier.

\section{Effect on mortality}

Results from randomized clinical trials

No single study or meta-analysis has reported a decreased overall mortality related to SUP approaches. To our knowledge, Krag and colleagues ${ }^{59}$ have published the most recent meta-analysis of randomized clinical trials comparing SUP versus placebo or no prophylaxis in 2014. In this analysis, 20 trials totalling 1,971 patients were included; all studies were judged as being at high risk of bias as advised by the Cochrane Collaboration. Among these 20 randomized controlled trials (RCTs), 16 were single-centre trials, 18 assessed H2RAs and two assessed PPIs. Using overall mortality as a primary end point, no statistically significant difference was reported between patients receiving SUP and those receiving no prophylaxis or placebo (fixed effect relative risk [RR] 1.00; 95\% CI 0.84-1.20; $\left.P=0.87 ; \mathrm{I}^{2}=0 \%\right) .{ }^{59}$ Similarly, no difference was observed between treatment versus placebo across all subgroup analyses; for example when assessing H2RAs or PPIs, or patients fed enterally or not. Of note, after the inclusion of old studies (16 of 20 were published before 1994), the meta-analysis mostly assessed H2RAs and was unable to accurately compare PPIs to H2RAs. Furthermore, in two meta-analyses published in 2012 and 2013-which included 13 RCTs totalling 1,587 patients $^{10}$ and 14 RCTs totalling 1,720 patients, ${ }^{12}$ respectively-PPIs were not found to be more effective than H2RAs in reducing overall mortality (ICU mortality $\mathrm{OR}=1.19$; 95\% CI $0.84-1.68$ and $\mathrm{RR}=1.01$; 95\% CI $0.83-1.24$, respectively). A study by Kotlyanskaya et al. ${ }^{60}$ (published in abstract form) was not included in the meta-analysis by Barkun et al. ${ }^{10}$ and is the only difference between the two meta-analyses.

\section{Data from observational cohorts}

Few reports are available on the effect of SUP on overall or ICU mortality rates. A retrospective cohort study, published in 2014, used information from the Colorado Multiple Institutional Review Board and analysed data from 35,312 patients requiring mechanical ventilation for $>24$ h. ${ }^{38}$ Propensity-score-adjusted and propensityscore-matched multivariate regression models suggested that PPIs were associated with an increased risk of death in the ICU compared with H2RAs (15.3\% versus $12.3 \%$, respectively; $P<0.001) .{ }^{38}$ Unfortunately, this study cannot conclude on causation because of its design and the inability to completely remove confounding factors; moreover, the authors did not assess patients in the ICU who did not receive SUP and thus the net effect of PPIs or H2RA cannot be estimated.

\section{Prevention of bleeding}

\section{Results from randomized clinical trials}

Results are more consistent in supporting a role for SUP in reducing the risk of gastrointestinal bleeding. In the Krag et al. ${ }^{59}$ meta-analysis, the risk of bleeding in the ICU was reduced by $59 \%$ (fixed effect RR $0.41 ; 95 \%$ CI $0.31-$ 0.53 ) in patients treated with SUP compared with those treated with placebo or no prophylaxis. Interestingly, the meta-analysis by Barkun et al. ${ }^{10}$ suggested the same magnitude of reduced risk of bleeding in patients treated with PPIs compared with those treated with H2RAs $(\mathrm{OR}=0.30$; 95\% CI 0.17-0.54), as did the meta-analysis by Alhazzani et al., ${ }^{12}$ showing that both clinically important $\mathrm{RR}=0.36$; 95\% CI 0.19-0.68) and overt bleeding (RR 0.35 ; $95 \%$ CI $0.21-0.59$ ) were reduced in patients treated with PPIs compared with those treated with H2RAs. On the contrary, another meta-analysis published in 2010 did not find strong arguments in favour of PPIs over H2RAs for stress-related UGIB or for mortality. ${ }^{13}$

\section{Data from observational cohorts}

SUP has become the standard of care in the ICU, sometimes irrespective of the presence of risk factors; the benefit of SUP using real-world data is therefore not easy to estimate because of the absence of a control group. A retrospective single-centre German study published in 2014 , in which $91.3 \%$ of the patients received SUP (mostly PPIs), did not suggest any difference in terms of bleeding between no treatment and any of the SUP 


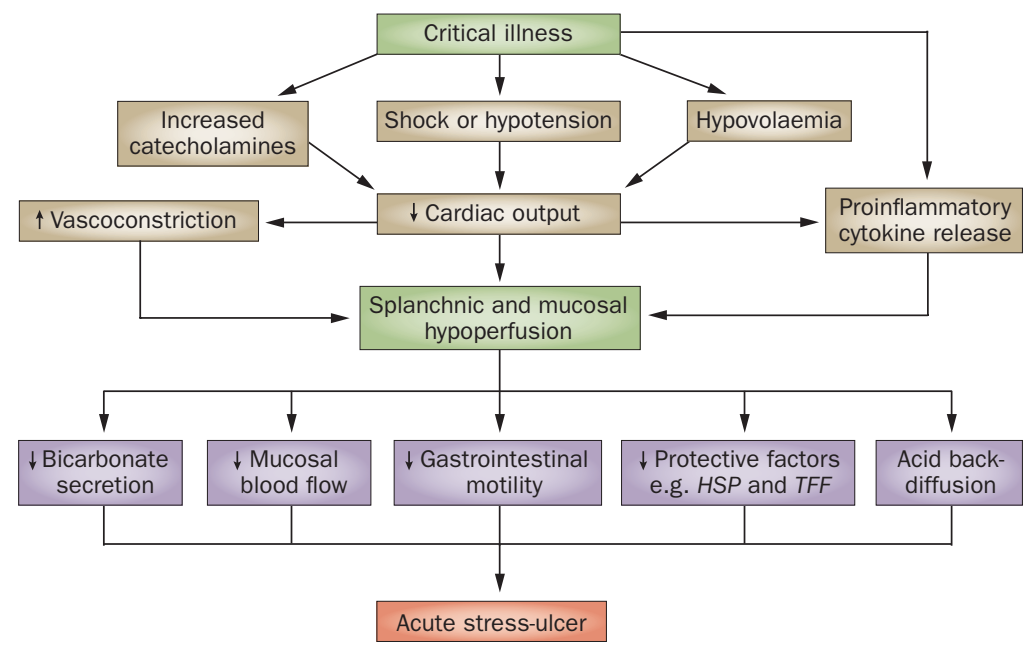

Figure 1 | Pathophysiology of stress-ulcer bleeding. Abbreviations: HSP, heat shock proteins; TFF, trefoil factor family peptides. Adapted with permission from Elsevier (c) Stollman, N. \& Metz, D, J. Crit. Care 20, 35-45 (2005).

agents that were used (including combinations of PPIs and H2RAs, PPIs and sucralfate or any other combination). ${ }^{6}$ The retrospective cohort study by MacLaren et al., ${ }^{38}$ described earlier, suggested that PPIs were associated with a greater risk of gastrointestinal haemorrhage than H2RAs (34\% versus $30.7 \%$, respectively; $P<0.001$ ). As this finding contradicts the hypothesis that stronger acid suppression reduces gastrointestinal bleeding, the study authors suggest that whereas both drug classes inhibit acid production, H2RAs might also limit reperfusion injury, possibly reducing oxidative stress after mucosal injury. ${ }^{38}$ To conclude, in patients with recognized risk factors, good evidence supports the use of PPIs to prevent stress-ulcer bleeding.

\section{Evidence for adverse events caused by SUP}

The acidity of gastric contents represents the major control factor for bacterial survival in the stomach. Gastric and duodenal bacterial overgrowth frequently occurs in conditions characterized by diminished gastric acid secretion. ${ }^{61}$ Thorens et al. ${ }^{62}$ conducted an RCT in which 47 outpatients were randomly allocated to receive 4 weeks of $20 \mathrm{mg}$ omeprazole or $800 \mathrm{mg}$ cimetidine, daily. Bacterial overgrowth, assessed by culture of gastroduodenal contents, was present in $53 \%$ of the patients receiving omeprazole and $17 \%$ of those receiving cimetidine. A subsequent study also showed that both PPIs and H2RAs induced bacterial overgrowth, with a substantially more-pronounced effect with PPIs than H2RAs. ${ }^{63}$ Furthermore, leucocyte function might be impaired in patients taking PPIs because of an inhibition of reactive oxygen intermediate production with consequential reduction of neutrophil bactericidal activity. ${ }^{64}$ The two types of infections most frequently discussed with the use of acid-suppressive agents are nosocomial (or ventilator-associated) pneumonia and diarrhoea associated with Clostridium difficile infection. The association between the use of acid-suppressive agents and community-acquired or hospital-acquired infections, ${ }^{10,65-67}$ and C. difficile infection and recurrence, ${ }^{68-73}$ are sources of ongoing controversy because of methodological limitations in study design.

\section{Results from randomized clinical trials}

Two meta-analyses published in 2012 and 2013 of RCTs comparing SUP agents did not provide evidence of an increased risk of nosocomial pneumonia attributable to PPIs. Indeed, the ORs were 1.05 (95\% CI 0.69-1.62) ${ }^{10}$ and 1.06 (95\% CI 0.73-1.52). ${ }^{12}$ Interpretation of these results must be performed with caution as only seven studies reported on nosocomial pneumonia. Interestingly, the meta-analysis that compared prophylaxis to placebo or no prophylaxis did not suggest any increased risk of nosocomial pneumonia in the prophylaxis group (RR 1.16; 95\% CI 0.84-1.58). ${ }^{59}$ One RCT conducted from 2010 to 2011 in Iran, in which 137 patients on mechanical ventilation were randomly assigned treatment with sucralfate or pantoprazole, found a significant increase in the incidence of pneumonia in the pantoprazole group (36.4\% versus $14.1 \%$, respectively; $P<0.001) .{ }^{74}$ Again, results from this study must be interpreted with caution because of methodological issues. No evidence exists regarding the risk of $C$. difficile infection related to SUP as this association was not a reported outcome in any of the RCTs.

\section{Data from observational cohorts}

A 1 day prevalence study conducted in 17 European countries in which 1,417 ICUs provided reports from 10,038 patients showed that 4,501 (44.8\%) patients had infections, 2,064 (20.6\%) of which were ICUacquired infections, with Enterobacteriaceae (34.4\%), Staphylociccus aureus $(30.1 \%)$ and Pseudomonas aeruginosa $(28.7 \%)$ being the three most frequent. ${ }^{75}$ Pneumonia was the most frequent site of infection, accounting for $47 \%$ of the patients. SUP was an independent risk factor for infection (OR 1.38; 95\% CI 1.20-1.60). ${ }^{75}$ Buendgens et al. ${ }^{6}$ found that PPIs were associated with the occurrence of pneumonia in univariate analysis (OR 1.79; 95\% CI 1.47-2.02) but not in multivariate analysis (OR 1.28; 95\% CI 0.95-1.73). Sucralfate was confirmed to have a protective effect against infection (OR 0.68; 95\% CI 0.50-0.73). ${ }^{6}$ MacLaren et al. ${ }^{38}$ only compared PPIs to H2RAs, finding that PPIs were associated with a significant increase in ICU-acquired pneumonia incidence (34\% versus $30.7 \%$, respectively; $P<0.001)$. A case-control study of 110 patients with ventilator-associated pneumonia and 110 ventilated controls without pneumonia did not find SUP to be a significant risk factor for pneumonia (OR $1.01 ; 95 \%$ CI $1.00-1.02 ; P=0.08) .{ }^{76}$

Cohort or case-control studies published within the past 10 years almost unanimously suggest an increased risk of acquiring C. difficile infection in patients receiving SUP in the ICU, even if the absolute risk is small compared with that for nosocomial pneumonia. A casecontrol study including 67 patients and 134 controls (20 controls and 40 patients with $C$. difficile infecction were ICU patients) reported duration of PPI use to be positively associated with the risk of developing C. difficile 
infection (OR 1.14; 95\% CI 1.02-1.27). ${ }^{77}$ Buendgens et al. ${ }^{6}$ reported an OR of 3.11 (95\% CI 1.11-8.44) for patients receiving PPIs versus no SUP, which is much stronger than the risk associated with the use of third-generation cephalosporins (OR 1.8; 95\% CI 1.0-3.23) or fluoroquinolone (OR 1.87; 95\% CI 1.1-3.14); no such risk was described for H2RAs. MacLaren et al. ${ }^{38}$ also suggested the risk of $C$. difficile infection to be higher in patients on PPIs than H2RAs (3.4\% versus 2.6\%, respectively; $P=0.002)$. Interestingly, an online survey conducted among Australian and New Zealand intensive care physicians suggests that $C$. difficile is perceived as less of a threat ( $14 \%$ of the physicians perceived $C$. difficile as a threat) than ventilator-associated pneumonia ( $21 \%$ of the physicians). ${ }^{78}$

\section{Risk:benefit ratio of SUP}

Defining the risk:benefit ratio of SUP in patients who are critically ill or on mechanical ventilation is not easy, as both bleeding and ICU-acquired infections carry a risk of increased death in ICU (OR 1.59; 95\% CI 1.06-2.41 C. difficile-associated diarrhoea; OR 1.82; 95\% CI 1.522.18 nosocomial infection; OR 2.5; 95\% CI 1.19-5.25 UGIB). ${ }^{6}$ Overall, mortality might be the best reflection of a risk:benefit analysis. Meta-analyses from RCTs report no effect on mortality, whereas data from observational studies suggest-although not unanimously—that PPIs might increase mortality compared with H2RAs. ${ }^{38}$ Nevertheless, as there are strong arguments in favour of a protective effect of PPIs in the prophylaxis of stress-ulcer bleeding, with no clearly proven increased risk of adverse events, the risk:benefit ratio of SUP in high-risk patients can be considered positive.

\section{Actual trends in SRMD prophylaxis}

Despite the vast number of publications on the topic that have defined the most relevant risk factors for SRMD and discussed the use of sucralfate, PPIs or H2RAs, epidemiological studies published in 2014 highlight that the proportion of patients in ICU receiving SUP is $>90 \%$ and although most of them receive PPIs, a substantial proportion (up to $20 \%$ ) receive a combination of different medications, including PPIs and H2RAs., ${ }^{6,38,79}$ Additionally, it has been shown that, although most of the patients receiving SUP in ICU present with at least one recognized risk factor, continuation of acidsuppressive therapy during hospitalization outside the ICU occurs in $>86 \%$ of patients and that $24.2 \%$ are being discharged from the hospital still receiving acidsuppressive therapy ${ }^{80}$ The cost implications of this issue are discussed later.

Among patients with no risk factors it is indeed of concern that up to $68.1 \%$ are being placed on prophylaxis at ICU admission; $60.4 \%$ continue treatment upon transfer from the ICU and about $30 \%$ are being discharged home on an agent without a new indication. ${ }^{79,81}$

In conclusion, it seems reasonable to recommend SUP (preferably with PPIs) in high-risk patients, that is, those with well-defined risk factors such as mechanical ventilation for at least $48 \mathrm{~h}$ and coagulation disorders.
For patients receiving enteral nutrition or medication of any type there is no reason to prescribe intravenous PPIs, enteral route is the most appropriate. SUP should not be given to low-risk patients because of the potential increased risk of nosocomial infection.

\section{Enteral nutrition for prophylaxis of SRMD}

The use of acid blockers or antisecretory agents in patients in the ICU has been questioned because of uncertain efficacy and safety concerns. Furthermore, the rationale for PPI or H2RA use might be considered weak as decreased mucosal blood flow with subsequent tissue ischaemia is thought to be the mechanism responsible for stress-induced gastropathy, with an amplification loop driven by subsequent activation of inflammatory and vasoconstrictive mediators, a mechanism that PPIs and/or H2RA are unlikely to have an effect on. Enteral nutrition has been suggested to improve mucosal blood flow and reverse the generation of these inflammatory mediators. ${ }^{82}$ However, clinical studies evaluating the effectiveness of enteral nutrition versus acid-suppressive medications have shown variable results. ${ }^{83}$ No RCTs to date have assessed enteral nutrition as SRMD-related bleeding prophylaxis in critically ill patients. One RCT published in the early 1990s only described that additional prophylaxis in the form of sucralfate or ranitidine added no protective effect to total parenteral nutrition alone. ${ }^{84}$

Marik et al. ${ }^{1}$ performed a systematic review of the literature to investigate the benefits and risks of SUP in the ICU setting and the possible influence of enteral nutrition. A total of 1,836 patients across 17 studies were included in the analysis and they found that the reduced risk of gastrointestinal bleeding with H2RAs (OR 0.47; 95\% CI 0.29-0.76) was only observed in patients not receiving enteral nutrition. Furthermore, whereas H2RAs apparently did not carry an increased risk of nosocomial pneumonia in fasting patients, a significant increase in risk was observed among enterally fed patients (OR 2.81; 95\% CI 1.2-6.56; $P=0.02$ ). ${ }^{1}$ Similarly, hospital mortality was also found to be increased in patients receiving enteral nutrition and H2RA therapy (OR 1.89; 95\% CI 1.04-3.44; $P=0.04$ ), suggesting that SUP might be unnecessary and possibly deleterious in this patient population. ${ }^{1}$ Interestingly, studies originating from the same team have suggested that enteral feeding can either have no effect on clinically important bleeding (multiple regression OR 1.0; $P=0.99),{ }^{4}$ or may decrease the risk by $70 \%$ (OR: $0.30 ; 95 \%$ CI $0.13-0.67 ; P=n s) .{ }^{20}$ Unfortunately, shortcomings in the identification of who had received enteral nutrition and the lack of per-patient analyses limit any conclusions that can be made.

\section{Management of UGIB in the ICU Critical care physician perspective}

Most of the guidelines that have been published on managing gastrointestinal bleeding in the ICU are based on the non-ICU literature as there is not enough supporting evidence to specifically develop treatment paths. ${ }^{85,86}$ An urgent need exists to produce evidence as some of the 
guidelines published outside the ICU setting ${ }^{87}$ might not be adaptable to patients bleeding in ICU. We describe the management of UGIB in the ICU on the basis of expert opinion.

The management of patients with SRMD is similar to that of other patients in the ICU presenting with nonvariceal UGIB, keeping in mind the commonly more severe disease acuity and multiple comorbidities often present in this ICU patient population. Detailed reviews and contemporary consensus recommendations have been published on the management of patients with nonvariceal UGIB. ${ }^{85,87-89}$ The approach might, of course, be altered if the critically ill patient is suspected to have variceal bleeding..$^{90}$ Although airway, breathing and circulation remain the most crucial steps in the initial assessment of patients presenting with acute UGIB, these factors have usually already been optimized in an ICU setting. A minimum blood work-up in all patients should include bloodtyping and crossmatching for an appropriate number of units of packed red blood cells along with determinations of haemoglobin, haematocrit, platelets and electrolyte levels, and coagulation time. Depending on the severity of the acute bleed and if it is indicated (mainly when prothrombin time and factor $\mathrm{V}$ are $<50 \%$ of the normal range), prompt and appropriate resuscitation with either crystalloids or colloids, packed red blood cells and fresh frozen plasma, is required. ${ }^{87,88}$

Vitamin K, vitamin-K-dependent factors or fibrinogen are usually administered in case of anticoagulant supratherapeutic dosing. Saline or Ringer acetate are preferred to hydroxyethyl starch, as hydroxyethyl starch has been shown to increase the need for renal-replacement therapy in patients in the ICU and might even increase the risk of severe bleeding (RR 1.52; 95\% CI 0.94-2.48; $P=0.09) .{ }^{91,92}$ A systematic review of 10 RCTs comparing restrictive versus liberal red blood cell transfusion strategies in 1,780 patients with suspected UGIB from a variety of clinical settings, including the ICU and patients with SRMD, concluded that a restrictive approach led to a $42 \%$ reduction in the probability of receiving transfusions with no effect on mortality, rates of cardiac events, morbidity, or length of hospital stay. ${ }^{93}$ These data support a restrictive strategy with a haemoglobin transfusional threshold value of $<70 \mathrm{~g} / \mathrm{l}$ for transfusion, which is further strengthened by the results of a recent large RCT in patients with variceal and nonvariceal UGIB published in 2013. ${ }^{94}$ Nevertheless, in critically ill patients a haemoglobin transfusional level $\sim 90 \mathrm{~g} / 1$ has been proposed, mostly in case of coronary artery disease, ${ }^{95}$ although red blood cell transfusion increases oxygen delivery but not oxygen consumption. ${ }^{96}$ The objective is to maintain mean arterial pressure $>65 \mathrm{mmHg}$ and urinary excretion $>0.5 \mathrm{ml} / \mathrm{kg} / \mathrm{h}$.

Placement of a nasogastric tube might be appropriate in the ICU, mostly to assess for rebleeding as altered gastrointestinal motility and the use of vasopressive drugs might delay exteriorization of bleeding or haemodynamic changes. However, as the negative predictive value of a nasogastric tube aspirate is low, around $60 \%$, its usefulness is questioned. ${ }^{97}$
Enteral nutrition must be stopped and gastric content removed with soft aspiration to enable gastroscopy, or prokinetic agents considered, as discussed later. For the same reason, sedation and analgesia should be reinforced in patients receiving mechanical ventilation. In patients on anticoagulants, coagulopathy is usually reversed, using vitamin $\mathrm{K}$, vitamin-K-dependent factors or fibrinogen; however, this process should not delay early endoscopy, defined as within $24 \mathrm{~h}$ of acute UGIB, keeping in mind that endoscopic haemostasis can be safely performed in patients with an elevated INR as long as it is not supratherapeutic (that is, up to around 2.5).$^{87,88}$ A platelet transfusion threshold of $50 \times 10^{9} / 1$ has been proposed for most patients, with a target of $100 \times 10^{9} / 1$ for patients in whom platelet dysfunction is suspected..$^{98}$

Well-validated risk stratification scoring systems in the setting of UGIB can help identify the ideal time to perform endoscopy. ${ }^{99}$ The Rockall score can be calculated using data for seven pre-endoscopic factors (clinical Rockall) and 11 postendoscopic factors. ${ }^{100}$ The use of prokinetics before endoscopy might be considered in selected patients. Indeed, meta-analyses show that erythromycin is associated with a decreased need for repeat endoscopy in patients with evidence of ongoing active bleeding and blood in the stomach (haematemesis, coffee ground vomiting, or bloody nasogastric aspirate). ${ }^{101}$ However, use of erythromycin has failed to change outcomes in terms of length of stay, transfusion requirements and need for surgery in patients with nonvariceal UGIB.

Although many patients might already be on a PPI in the ICU, it is nonetheless pertinent that a Cochrane systematic meta-analysis found no evidence that pre-endoscopic administration of PPIs led to a reduction in the most important clinical outcomes, but this practice does result in a downstaging of high-risk endoscopic ulcers into low-risk lesions. ${ }^{102}$ Therefore, this approach might be cost-effective when early endoscopy is not feasible or local expertise is limited. The use of pre-endoscopic PPIs, however, should not replace appropriate initial resuscitation or delay the performance of early endoscopy. ${ }^{103}$ The optimal dose remains unknown but many clinicians choose to use the high-dose intravenous PPI infusion of an $80 \mathrm{mg}$ bolus followed by $8 \mathrm{mg} / \mathrm{h}$ infusion, ${ }^{104}$ as the highest quality evidence comes from trials using this regimen.

\section{The gastroenterologist perspective}

On the basis of RCT data, current management recommendations for UGIB suggest the performance of early endoscopy within $24 \mathrm{~h}$ of presentation..$^{87,88}$ In the ICU a more urgent endoscopy might be considered as it has been suggested that in patients with a GlasgowBlatchford score $>12$, mortality is reduced when endoscopy is performed within the first $13 \mathrm{~h} .{ }^{105}$ In patients with massive haematochezia and/or in case of haemodynamic instability guidelines published in 2006 recommend performing upper endoscopy as soon as possible in the presence of this symptom as it will be a presenting feature in $\sim 10 \%$ of patients ultimately found to have an upper gastrointestinal source of bleeding. ${ }^{106}$ The treatment of ulcers (if noted at endoscopy) is well defined 
and outlined later. The treatment of other lesions, such as Dieulafoy ulcers or mucosal vascular abnormalities has been less well studied, but in the presence of one or multiple lesions that are thought to be the source of bleeding, an assessment of the presence of high-risk stigmata of the lesion(s) is performed. Whether gastroduodenal ulcers, erosions or oesophagitis are noted, if only low-risk stigmata are present, single intravenous PPI therapy is indicated without endoscopic haemostasis. Endoscopic therapy is recommended only for high-risk endoscopic lesions and is the cornerstone of management with modalities that include injection, mechanical and thermal treatments. ${ }^{87,88}$ Haemostatic powders have now been adapted for use in the gastrointestinal tract, ${ }^{107}$ resulting in substantial reductions in rebleeding in select patients, but reported benefits on mortality and rates of surgical intervention are variable, although the data are purely observational and patient numbers are limited. ${ }^{87,88}$ Following successful endoscopic haemostasis, PPI therapy has further improved outcomes. A highdose intravenous PPI approach has been favoured by guidelines ( $80 \mathrm{mg}$ bolus if the patient has not been on a PPI, followed by $8 \mathrm{mg} / \mathrm{h}$ for $72 \mathrm{~h}$ ); however, the optimal dose and route of administration remain unclear. ${ }^{87,88}$

The acute management of patients on antiplatelet agents is based on weighing risks and benefits, but RCT data support the early reintroduction of acetylsalicylic acid within 3-5 days of the acute haemorrhage in patients with bleeding ulcers who are taking acetylsalicylic acid for secondary cardiovascular disease prevention. ${ }^{108}$ The theoretical interaction between clopidogrel and PPI seems unlikely to be of clinical importance and should not deter physicians from administering PPIs, if clinically indicated. ${ }^{109}$ The long-term secondary prophylaxis of patients with SRMD-related bleeding has not been studied, but it is reasonable to at least consider applying the same recommendations as for bleeding ulcers occurring outside the ICU. However, discussion of this idea is beyond the scope of this Review. ${ }^{87,88}$

\section{Cost considerations and guidelines}

In 1995, a Canadian matched cohort study identified clinically important bleeding to be associated with per patient costs of $\sim \mathrm{CND} \$ 12,215 .{ }^{110}$ Schupp et al. ${ }^{111}$ subsequently performed an economic analysis, but unfortunately limited the costs solely to drug acquisition. More important cost-drivers are known to include possible complications of SRMD and its prophylaxis, ${ }^{112}$ daily costs and duration of hospital stay, especially in the ICU.

Two decision models have assessed the costeffectiveness of SRMD prophylaxis using either H2RA or PPI therapies during hospitalization. One study concluded that H2RA therapy seems to reduce costs with comparable survival benefit compared with PPIs for SUP. ${ }^{113}$ However, this study adopted mortality as a primary effectiveness measure, an outcome that has not been shown to be affected by SRMD prophylaxis, as discussed earlier. ${ }^{10,12}$ Also, this analysis included the possible complication of $C$. difficile infection, even though this association with PPI use remains highly debated in the hospital setting. ${ }^{114}$ The second decision model concluded that PPI prophylaxis was the most cost-effective, in fact economically dominant, prophylactic strategy. ${ }^{115}$ However, in both cost-effectiveness analyses, the probability of ventilator-associated pneumonia occurrence affected the aforementioned conclusions even though it remains controversial as to whether or not acid suppression increases the risk of this iatrogenic complication. The discrepancy in these conclusions highlights the poor quality, small sample sizes and limited generalizability of contemporary care trials, emphasizing the need for prospective controlled assessments of both bleeding and possible infectious complications.

A number of society guidelines have been published over the past 15 years in an attempt to optimally guide acid-suppression use for SRMD prophylaxis, with most published before the flurry of meta-analytical studies discussed above. These society guidelines include an authoritative set of recommendations by the American Society for Health-System Pharmacists that were developed for the most part before the PPI era. ${ }^{116}$ In 2008, the Eastern Association for the Surgery of Trauma guidelines suggested no differences in efficacy between H2RAs and PPIs. ${ }^{117}$ In 2013, although no specific trials have investigated the benefit of SUP in patients with sepsis, the Surviving Sepsis Campaign guidelines favoured the use of PPIs over H2RAs for SRMD prophylaxis. ${ }^{96}$

Although uncertainty exists about the optimal strategy for effective SRMD prophylaxis in high-risk patients, it is well established that antisecretory therapy is not warranted in patients at low risk, as discussed earlier. Although the definitions of inappropriate use have varied among studies and with the publication of the latest meta-analytical data, inappropriate in-hospital use is common. Outside the ICU, in-hospital PPI use has been shown to vary between $50 \%$ and $60 \%$ of patients, with $18-34 \%$ of patients erroneously discharged on a PPI into the community with attendant inpatient and outpatient costs. ${ }^{77}$ A retrospective chart review of 1,769 patients admitted to family medicine and general internal medicine teaching services demonstrated an inappropriate in-hospital acid-suppressive agent use of $22.1 \%$ (presumably in large part because of unjustified concerns of SRMD). ${ }^{118}$ In total, $54 \%$ of these patients were discharged on antisecretory medication that were deemed unnecessary upon audit review, with an estimated annual inpatient and outpatient cost of US\$67,000. A 2010 analysis of a US national administrative database demonstrated a $\sim 69 \%$ rate of inappropriate prescribing for SRMD prophylaxis in ICU or Coronary Care Unit. ${ }^{119}$ Resulting overall hospital and discharge medication costs might reach US $\$ 753,267$ per year nationally over the 30 days after leaving the hospital. ${ }^{118}$

Although early interventional studies suggested that the implementation of guidelines might impact favourably on practice and resource utilization in the ICU, ${ }^{120,121}$ a 2013 national cluster RCT demonstrated no differences in hospital use of PPIs for nonvariceal UGIB following a structured multidisciplinary multifaceted educational intervention. ${ }^{122}$ 


\section{New approaches}

New therapeutic approaches might be assessed based on an improved understanding of the underlying mechanisms. For example, increasing gastrointestinal microvascular blood flow might be beneficial. As discussed previously, improved management of cardiac output in the ICU can explain the decrease in SRMD over time, although the link between recognized risk factors, such as sepsis, and SRMD might not involve decreased microcirculation. ${ }^{123}$ As reported in a 2014 review, several studies have attempted to increase microcirculatory flow parameters but with limited efficacy. ${ }^{124}$ Other pharmacological options to prevent SRMD can be hypothesized based on its pathophysiology. For example, gastric bicarbonate secretion is stimulated by nitric oxide in a process that involves cyclic GMP, under the control of phosphodiesterase 1 and 5; phosphodiesterase 5 inhibitors, such as sildenafil, might increase bicarbonate secretion. Additionally, phosphodiesterase 5 inhibitors might increase mucosal blood flow, as it has been shown that vardenafil protects the digestive tract after ischaemiareperfusion injury. ${ }^{125}$ As HSPs (mostly HSP70) protect the gastric mucosa through inhibition of apoptosis, proinflammatory cytokines and cell adhesion molecules, regulators that enhance HSP70 expression could represent interesting agents for the prevention of SRMD. Unfortunately, most of the HSP70-targeted compounds that are being developed are inhibitors. ${ }^{126}$ Moreover, it is highly challenging to design and power clinical trials aimed to compare new therapeutic options to PPIs or H2RAs. Indeed, with an actual prevalence of SMRD of $\sim 1 \%$, more than 10,000 patients would have to be included to prove a $50 \%$ relative risk reduction.

\section{Conclusions}

Stress-ulcer bleeding is an increasingly less frequent condition in the contemporary era of markedly improved overall care for critically ill patients. However, SRMD is still associated with substantial mortality and costs, and prospective trials comparing modern-day prophylactic approaches, including enteral nutrition, are needed. The almost universal (>90\%) prescription of SUP in critically ill patients must be questioned and the risk:benefit ratio reassessed because of the decrease in incidence of SMRD. In addition to randomized trials, there is a need for prospective cohort studies to better quantify and understand outcomes in the real-word setting.

Treatment strategies need to be evaluated on a caseby-case basis, taking into account the expected benefits of therapy balanced against the patient's risk factors for bleeding and the risk of nosocomial pneumonia or C. difficile infection in the local epidemiological context. Generally speaking, SUP is not warranted in non-ICU patients, except where confirmed clinical indications exist. Educational programmes are needed to decrease unjustified overuse of SUP in patients in ICUs ${ }^{127}$ and promote appropriate treatment discontinuation after ICU and upon hospital discharge.

Review criteria
We conducted a literature search using the OVID,
MEDLINE, EMBASE, PubMed, and ISI Web of Knowledge
4.0 databases to identify articles published in English or
French from January 1994 to $15^{\text {th }}$ October 2014 . A highly
sensitive search strategy was used to identify randomized
controlled trials, cohort and case-control studies
conducted in adults, using combinations of search terms,
including: "stress ulcer bleeding", "stress related mucosal
lesion", "stress related mucosal disease", "stress
ulcer", "gastroduodenal damages", "intensive care unit",
"critically ill", "epidemiology", "prevention", "prophylaxis",
"guidelines", "histamine-2 receptor antagonists",
"sucralfate" and "proton pump inhibitors". In addition,
recursive searches and cross-referencing were performed
and manual searches of the reference lists of articles
identified in the initial search were completed.

1. Marik, P. E., Vasu, T., Hirani, A. \& Pachinburavan, M. Stress ulcer prophylaxis in the new millennium: a systematic review and meta-analysis. Crit. Care Med. 38, 2222-2228 (2010).

2. Laine, L., Takeuchi, K. \& Tarnawski, A. Gastric mucosal defense and cytoprotection: bench to bedside. Gastroenterology 135, 41-60 (2008).

3. Laine, L. et al. Lower gastrointestinal events in a double-blind trial of the cyclo-oxygenase-2 selective inhibitor etoricoxib and the traditional nonsteroidal anti-inflammatory drug diclofenac. Gastroenterology 135, 1517-1525 (2008).

4. Cook, D. J. et al. Risk factors for gastrointestinal bleeding in critically ill patients. Canadian Critical Care Trials Group. N. Engl. J. Med. 330, 377-381 (1994).

5. Reintam Blaser, A. et al. Gastrointestinal symptoms during the first week of intensive care are associated with poor outcome: a prospective multicentre study. Intensive Care Med. 39, 899-909 (2013).

6. Buendgens, L. et al. Administration of proton pump inhibitors in critically ill medical patients is associated with increased risk of developing Clostridium difficile-associated diarrhea. J. Crit. Care 29, 696.e11-696.e15 (2014).
7. Spirt, M. J. Stress-related mucosal disease: risk factors and prophylactic therapy. Clin. Ther. 26, 197-213 (2004).

8. Stollman, N. \& Metz, D. C. Pathophysiology and prophylaxis of stress ulcer in intensive care unit patients. J. Crit. Care 20, 35-45 (2005).

9. Masson, S. C., Mabasa, V. H., Malyuk, D. L. \& Perrott, J. L. Validity evidence for FASTHUGMAIDENS, a mnemonic for identifying drugrelated problems in the intensive care unit. Can. J. Hosp. Pharm. 66, 157-162 (2013).

10. Barkun, A. N., Bardou, M., Pham, C. Q. $\&$ Martel, M. Proton pump inhibitors vs. histamine 2 receptor antagonists for stressrelated mucosal bleeding prophylaxis in critically ill patients: a meta-analysis. Am. J. Gastroenterol. 107, 507-520 (2012)

11. Leontiadis, G. I. et al. Systematic reviews of the clinical effectiveness and cost-effectiveness of proton pump inhibitors in acute upper gastrointestinal bleeding. Health Technol. Assess. 11, 1-164 (2007).

12. Alhazzani, W., Alenezi, F., Jaeschke, R. Z., Moayyedi, P. \& Cook, D. J. Proton pump inhibitors versus histamine 2 receptor antagonists for stress ulcer prophylaxis in critically ill patients: a systematic review and meta-analysis. Crit. Care Med. 41, 693-705 (2013).

13. Lin, P. C., Chang, C. H., Hsu, P. I., Tseng, P. L. \& Huang, Y. B. The efficacy and safety of proton pump inhibitors vs histamine- 2 receptor antagonists for stress ulcer bleeding prophylaxis among critical care patients: a meta-analysis. Crit. Care Med. 38, 1197-1205 (2010).

14. Peura, D. A. \& Johnson, L. F. Cimetidine for prevention and treatment of gastroduodenal mucosal lesions in patients in an intensive care unit. Ann. Intern. Med. 103, 173-177 (1985).

15. Skillman, J. J. \& Silen, W. Acute gastroduodenal "stress" ulceration: barrier disruption of varied pathogenesis? Gastroenterology 59, 478-482 (1970)

16. Zandstra, D. F. \& Stoutenbeek, C. P. The virtual absence of stress-ulceration related bleeding in ICU patients receiving prolonged mechanical ventilation without any prophylaxis. A prospective cohort study. Intensive Care Med. 20, 335-340 (1994).

17. Duerksen, D. R. Stress-related mucosal disease in critically ill patients. Best Pract. Res. Clin. Gastroenterol. 17, 327-344 (2003). 
18. Alhazzani, W., Alshahrani, M., Moayyedi, P. \& Jaeschke, R. Stress ulcer prophylaxis in critically ill patients: review of the evidence. Pol. Arch. Med. Wewn. 122, 107-114 (2012).

19. Zimmerman, J. E., Kramer, A. A. \& Knaus, W. A Changes in hospital mortality for United States intensive care unit admissions from 1988 to 2012. Crit. Care 17, R81 (2013).

20. Cook, D. et al. Risk factors for clinically important upper gastrointestinal bleeding in patients requiring mechanical ventilation. Canadian Critical Care Trials Group. Crit. Care Med. 27, 2812-2817 (1999).

21. Schuster, D. P., Rowley, H., Feinstein, S., McGue, M. K. \& Zuckerman, G. R. Prospective evaluation of the risk of upper gastrointestinal bleeding after admission to a medical intensive care unit. Am. J. Med. 76, 623-630 (1984).

22. Beejay, U. \& Wolfe, M. M. Acute gastrointestinal bleeding in the intensive care unit. The gastroenterologist's perspective. Gastroenterol. Clin. North Am. 29, 309-336 (2000).

23. Steinberg, K. P. Stress-related mucosal disease in the critically ill patient: risk factors and strategies to prevent stress-related bleeding in the intensive care unit. Crit. Care Med. 30, 362-364 (2002).

24. Daley, R. J., Rebuck, J. A., Welage, L. S. \& Rogers, F. B. Prevention of stress ulceration: current trends in critical care. Crit. Care Med. 32 , 2008-2013 (2004).

25. Quenot, J. P. et al. Bedside adherence to clinical practice guidelines in the intensive care unit: the TECLA study. Intensive Care Med. 34, 1393-1400 (2008).

26. Quenot, J. P., Thiery, N. \& Barbar, S. When should stress ulcer prophylaxis be used in the ICU? Curr. Opin. Crit. Care 15, 139-143 (2009).

27. Frandah, W., Colmer-Hamood, J., Nugent, K. \& Raj, R. Patterns of use of prophylaxis for stress-related mucosal disease in patients admitted to the intensive care unit. J. Intensive Care Med. 29, 96-103 (2014).

28. deFoneska, A. \& Kaunitz, J. D. Gastroduodenal mucosal defense. Curr. Opin. Gastroenterol. 26, 604-610 (2010).

29. Ferrer-Ferrer, M. et al. Polymorphisms in genes coding for HSP-70 are associated with gastric cancer and duodenal ulcer in a population at high risk of gastric cancer in Costa Rica. Arch. Med. Res. 44, 467-474 (2013).

30. Tahara, T. et al. Role of heat-shock protein (HSP) 70-72 genotype in peptic ulcer in Japanese population. Hepatogastroenterology 59, 426-429 (2012).

31. Takahashi, T. et al. Correlation of heat shock protein expression to gender difference in development of stress-induced gastric mucosal injury in rats. J. Clin. Biochem. Nutr. 47, 64-73 (2010).

32. Hawkey, C. J. \& Rampton, D. S. Prostaglandins and the gastrointestinal mucosa: are they important in its function, disease, or treatment? Gastroenterology 89, 1162-1188 (1985).

33. Flemstrom, G. \& Turnberg, L. A. Gastroduodenal defence mechanisms. Clin. Gastroenterol. 13, 327-354 (1984).

34. Phillipson, M., Atuma, C., Henriksnas, J. $\&$ Holm, L. The importance of mucus layers and bicarbonate transport in preservation of gastric juxtamucosal pH. Am. J. Physiol. Gastrointest. Liver Physiol. 282, 211-219 (2002)

35. Flynn, R. et al. Stress ulceration and gastric mucosal cell kinetics: the influence of prophylaxis against acute stress ulceration. J. Surg. Res. 55, 188-192 (1993).

36. Robert, A. Cytoprotection of the gastrointestinal mucosa. Adv. Intern. Med. 28, 325-337 (1983).
37. Fennerty, M. B. Pathophysiology of the upper gastrointestinal tract in the critically ill patient: rationale for the therapeutic benefits of acid suppression. Crit. Care Med. $\mathbf{3 0}$ (Suppl.), 351-355 (2002).

38. MacLaren, R., Reynolds, P. M. \& Allen, R. R. Histamine-2 receptor antagonists vs proton pump inhibitors on gastrointestinal tract hemorrhage and infectious complications in the intensive care unit. JAMA Intern. Med. 174, 564-574 (2014).

39. Chierego, M., Verdant, C. \& De Backer, D. Microcirculatory alterations in critically ill patients. Minerva Anestesiol. 72, 199-205 (2006).

40. Bailey, R. W. et al. The fundamental hemodynamic mechanism underlying gastric "stress ulceration" in cardiogenic shock. Ann. Surg. 205, 597-612 (1987).

41. Yasue, N. \& Guth, P. H. Role of exogenous acid and retransfusion in hemorrhagic shock-induced gastric lesions in the rat. Gastroenterology 94 , 1135-1143 (1988).

42. Cook, D. J. et al. The attributable mortality and length of intensive care unit stay of clinically important gastrointestinal bleeding in critically ill patients. Crit. Care 5, 368-375 (2001).

43. Mutlu, G. M., Mutlu, E. A. \& Factor, P. G complications in patients receiving mechanical ventilation. Chest 119, 1222-1241 (2001).

44. Martindale, R. G. Contemporary strategies for the prevention of stress-related mucosal bleeding. Am. J. Health Syst. Pharm. 62 (Suppl. 2), 11-17 (2005).

45. Perry, M. A., Wadhwa, S., Parks, D. A., Pickard, W. $\&$ Granger, D. N. Role of oxygen radicals in ischemia-induced lesions in the cat stomach. Gastroenterology 90, 362-367 (1986).

46. Stupak, D. P., Abdelsayed, G. G. \& Soloway, G. N. Motility disorders of the upper gastrointestinal tract in the intensive care unit: pathophysiology and contemporary management. J. Clin. Gastroenterol. 46, 449-456 (2012).

47. Haglund, U. Stress ulcers. Scand. J. Gastroenterol. Suppl. 175, 27-33 (1990).

48. Itoh, M. \& Guth, P. H. Role of oxygen-derived free radicals in hemorrhagic shock-induced gastric lesions in the rat. Gastroenterology $\mathbf{8 8}$, 1162-1167 (1985).

49. Smith, P., O'Brien, P., Fromm, D. \& Silen, W. Secretory state of gastric mucosa and resistance to injury by exogenous acid. Am. J. Surg. 133, 81-85 (1977).

50. Marrone, G. C. \& Silen, W. Pathogenesis, diagnosis and treatment of acute gastric mucosal lesions. Clin. Gastroenterol. 13, 635-650 (1984).

51. Dzienis, H., Gronbech, J. E., Varhaug, J. E., Lekven, J. \& Svanes, K. Regional blood flow and acid secretion associated with damage and restitution of the gastric surface epithelium in cats. Eur. Surg. Res. 19, 98-112 (1987).

52. Durham, R. M. \& Shapiro, M. J. Stress gastritis revisited. Surg. Clin. North Am. 71, 791-810 (1991).

53. Synnerstad, I., Johansson, M., Nylander, O. \& Holm, L. Intraluminal acid and gastric mucosal integrity: the importance of blood-borne bicarbonate. Am. J. Physiol. Gastrointest. Liver Physiol. 280, 121-129 (2001).

54. Szabo, S. Mechanisms of gastric mucosal injury and protection. J. Clin. Gastroenterol. 13 (Suppl. 2), 21-34 (1991).

55. Miller, T. A. Mechanisms of stress-related mucosal damage. Am. J. Med. 83, 8-14 (1987).

56. Goldin, G. F. \& Peura, D. A. Stress-related mucosal damage. What to do or not to do. Gastrointest. Endosc. Clin. N. Am. 6, 505-526 (1996).
57. Samloff, I. M. Peptic ulcer: the many proteinases of aggression. Gastroenterology 96, 586-595 (1989).

58. Schiessel, R., Feil, W. \& Wenzl, E. Mechanisms of stress ulceration and implications for treatment. Gastroenterol. Clin. North Am. 19, 101-120 (1990)

59. Krag, M., Perner, A., Wetterslev, J., Wise, M. P. \& Hylander Moller, M. Stress ulcer prophylaxis versus placebo or no prophylaxis in critically il patients. A systematic review of randomised clinical trials with meta-analysis and trial sequential analysis. Intensive Care Med. 40, 11-22 (2014).

60. Kotlyanskaya, A., Luka, B. \& Mukherji, R. A comparison of lansoprazole disintegrating tablet lansoprazole suspension or ranitidine for stress ulcer prophylaxis in critically ill patients [abstract 194]. Crit. Care Med. 7 (2008).

61. Drasar, B. S., Shiner, M. \& McLeod, G. M. Studies on the intestinal flora. I. The bacterial flora of the gastrointestinal tract in healthy and achlorhydric persons. Gastroenterology 56, 71-79 (1969).

62. Thorens, J. et al. Bacterial overgrowth during treatment with omeprazole compared with cimetidine: a prospective randomised double blind study. Gut 39, 54-59 (1996).

63. Wang, K. et al. The effect of H2-receptor antagonist and proton pump inhibitor on microbial proliferation in the stomach. Hepatogastroenterology 51, 1540-1543 (2004).

64. Zedtwitz-Liebenstein, K. et al. Omeprazole treatment diminishes intra- and extracellular neutrophil reactive oxygen production and bactericidal activity. Crit. Care Med. 30, 1118-1122 (2002).

65. Giuliano, C., Wilhelm, S. M. \& Kale-Pradhan, P. B. Are proton pump inhibitors associated with the development of community-acquired pneumonia? A meta-analysis. Expert Rev. Clin. Pharmacol. 5, 337-344 (2012).

66. Filion, K. B. et al. Proton pump inhibitors and the risk of hospitalisation for community-acquired pneumonia: replicated cohort studies with metaanalysis. Gut 63, 552-558 (2014).

67. Eom, C. S. et al. Use of acid-suppressive drugs and risk of pneumonia: a systematic review and meta-analysis. CMAJ 183, 310-319 (2011).

68. Dial, S., Delaney, J. A., Barkun, A. N. \& Suissa, S. Use of gastric acid-suppressive agents and the risk of community-acquired Clostridium difficileassociated disease. JAMA 294, 2989-2995 (2005)

69. Tleyjeh, I. M. et al. Association between proton pump inhibitor therapy and Clostridium difficile infection: a contemporary systematic review and meta-analysis. PLoS ONE 7, e50836 (2012).

70. Shivashankar, R. et al. Clinical factors associated with development of severecomplicated Clostridium difficile infection. Clin. Gastroenterol. Hepatol. 11, 1466-1471 (2013).

71. Janarthanan, S., Ditah, I., Adler, D. G. \& Ehrinpreis, M. N. Clostridium difficile-associated diarrhea and proton pump inhibitor therapy: a meta-analysis. Am. J. Gastroenterol. 107, 1001-1010 (2012).

72. Kwok, C. S. et al. Risk of Clostridium difficile infection with acid suppressing drugs and antibiotics: meta-analysis. Am. J. Gastroenterol. 107, 1011-1019 (2012)

73. Pant, C., Madonia, P. \& Minocha, A. Does PP therapy predispose to Clostridium difficile infection? Nat. Rev. Gastroenterol. Hepatol. 6 , 555-557 (2009).

74. Khorvash, F., Abbasi, S., Meidani, M., Dehdashti, F. \& Ataei, B. The comparison between proton pump inhibitors and sucralfate in incidence of ventilator associated pneumonia 
in critically ill patients. Adv. Biomed. Res. 3, 52 (2014).

75. Vincent, J. L. et al. The prevalence of nosocomial infection in intensive care units in Europe. Results of the European Prevalence of Infection in Intensive Care (EPIC) Study. EPIC Internationa Advisory Committee. JAMA 274, 639-644 (1995).

76. Lewis, S. C., Li, L., Murphy, M. V., Klompas, M. \& Epicenters, C. D. C. P. Risk factors for ventilator-associated events: a case-control multivariable analysis. Crit. Care Med. 42, 1839-1848 (2014).

77. Barletta, J. F., El-lbiary, S. Y., Davis, L. E., Nguyen, B. \& Raney, C. R. Proton pump inhibitors and the risk for hospital-acquired Clostridium difficile infection. Mayo Clin. Proc. 88, 1085-1090 (2013).

78. Eastwood, G. M. et al. Opinions and practice of stress ulcer prophylaxis in Australian and New Zealand intensive care units. Crit. Care Resusc. 16, 170-174 (2014).

79. Barletta, J. F. et al. Pharmacoepidemiology of stress ulcer prophylaxis in the United States and Canada. J. Crit. Care (2014).

80. Murphy, C. E. et al. Frequency of inappropriate continuation of acid suppressive therapy after discharge in patients who began therapy in the surgical intensive care unit. Pharmacotherapy 28, 968-976 (2008).

81. Farrell, C. P., Mercogliano, G. \& Kuntz, C. L. Overuse of stress ulcer prophylaxis in the critical care setting and beyond. J. Crit. Care 25, 214-220 (2010).

82. MacLaren, R., Jarvis, C. L. \& Fish, D. N. Use of enteral nutrition for stress ulcer prophylaxis. Ann. Pharmacother. 35, 1614-1623 (2001)

83. Hurt, R. T. et al. Stress prophylaxis in intensive care unit patients and the role of enteral nutrition. J. Parenter. Enteral. Nutr. 36, 721-731 (2012).

84. Ruiz-Santana, S. et al. Stress-induced gastroduodenal lesions and total parenteral nutrition in critically ill patients: frequency, complications, and the value of prophylactic treatment. A prospective, randomized study. Crit. Care Med. 19, 887-891 (1991).

85. Osman, D., Djibre, M., Da Silva, D. \& Goulenok, C. Management by the intensivist of gastrointestinal bleeding in adults and children. Ann. Intensive Care 2, 46 (2012).

86. Madsen, K. R. et al. Guideline for stress ulcer prophylaxis in the intensive care unit. Dan. Med. J. 61, C4811 (2014).

87. Barkun, A. N. et al. International consensus recommendations on the management of patients with nonvariceal upper gastrointestinal bleeding. Ann. Intern. Med. 152, 101-113 (2010)

88. Laine, L. \& Jensen, D. M. Management of patients with ulcer bleeding. Am. J. Gastroenterol. 107, 345-360 (2012).

89. Lu, Y., Loffroy, R., Lau, J. Y. \& Barkun, A. Multidisciplinary management strategies for acute non-variceal upper gastrointestina bleeding. Br. J. Surg. 101, 34-50 (2014).

90. Opio, C. K. \& Garcia-Tsao, G. Managing varices: drugs, bands, and shunts. Gastroenterol. Clin. North Am. 40, 561-579 (2011).

91. Myburgh, J. A. et al. Hydroxyethyl starch or saline for fluid resuscitation in intensive care. N. Engl. J. Med. 367, 1901-1911 (2012).

92. Perner, A. et al. Hydroxyethyl starch $130 / 0.42$ versus Ringer's acetate in severe sepsis. N. Engl. J. Med. 367, 124-134 (2012).
93. Jairath, V. et al. Red cell transfusion for the management of upper gastrointestinal haemorrhage. Cochrane Database of Systematic Reviews, Issue 9 Art. No.: CD006613. http:// dx.doi.org/10.1002/14651858.CD006613. pub3.

94. Villanueva, C. et al. Transfusion strategies for acute upper gastrointestinal bleeding. N. Engl. J. Med. 368, 11-21 (2013).

95. Hebert, P. C. \& Carson, J. L. Transfusion threshold of $7 \mathrm{~g}$ per deciliter-the new normal. N. Engl. J. Med. 371, 1459-1461 (2014).

96. Dellinger, R. P. et al. Surviving sepsis campaign: international guidelines for management of severe sepsis and septic shock, 2012. Crit. Care Med. 41, 580-637 (2013)

97. Palamidessi, N., Sinert, R., Falzon, L. $\&$ Zehtabchi, S. Nasogastric aspiration and lavage in emergency department patients with hematochezia or melena without hematemesis. Acad. Emerg. Med. 17, 126-132 (2010).

98. Razzaghi, A. \& Barkun, A. N. Platelet transfusion threshold in patients with upper gastrointestinal bleeding: a systematic review. J. Clin. Gastroenterol. 46, 482-486 (2012).

99. Gralnek, I. M., Barkun, A. N. \& Bardou, M. Management of acute bleeding from a peptic ulcer. N. Engl. J. Med. 359, 928-937 (2008).

100. Rockall, T. A., Logan, R. F., Devlin, H. B. \& Northfield, T. C. Risk assessment after acute upper gastrointestinal haemorrhage. Gut $\mathbf{3 8}$, 316-321 (1996).

101. Barkun, A. N., Bardou, M., Martel, M., Gralnek, I. M. \& Sung, J. J. Prokinetics in acute upper GI bleeding: a meta-analysis. Gastrointest. Endosc. 72, 1138-1145 (2010)

102. Sreedharan, A. et al. Proton pump inhibitor treatment initiated prior to endoscopic diagnosis in upper gastrointestinal bleeding. Cochrane Database Systematic Reviews, Issue 7 Art. No CD005415. http://dx.doi.org/10.1002/ 14651858.CD005415.pub3.

103. Barkun, A. N. Should every patient with suspected upper GI bleeding receive a proton pump inhibitor while awaiting endoscopy? Gastrointest. Endosc. 67, 1064-1066 (2008).

104. Lau, J. Y. et al. Omeprazole before endoscopy in patients with gastrointestinal bleeding. N. Engl. J. Med. 356, 1631-1640 (2007).

105. Lim, L. G. et al. Urgent endoscopy is associated with lower mortality in high-risk but not low-risk nonvariceal upper gastrointestinal bleeding. Endoscopy 43, 300-306 (2011)

106. Rockey, D. C. Lower gastrointestinal bleeding. Gastroenterology 130, 165-171 (2006).

107. Barkun, A. New topical hemostatic powders in endoscopy. Gastroenterol. Hepatol. (N.Y.) 9 744-746 (2013).

108. Sung, J. J. et al. Continuation of low-dose aspirin therapy in peptic ulcer bleeding: a randomized trial. Ann. Intern. Med. 152, 1-9 (2010).

109. de Aquino Lima, J. P. \& Brophy, J. M. Conflicting evidence: what's a clinician to do? Ann. Intern. Med. 153, 413-415 (2010).

110. Heyland, D. et al. Enteral nutrition in the critically ill patient: a prospective survey. Crit. Care Med. 23, 1055-1060 (1995).

111. Schupp, K. N., Schrand, L. M. \& Mutnick, A. H. A cost-effectiveness analysis of stress ulcer prophylaxis. Ann. Pharmacother. 37, 631-635 (2003).

112. Barletta, J. F. \& Sclar, D. A. Use of proton pump inhibitors for the provision of stress ulcer prophylaxis: clinical and economic consequences. Pharmacoeconomics 32, 5-13 (2014).
113. MacLaren, R. \& Campbell, J. Cost-effectiveness of histamine receptor-2 antagonist versus proton pump inhibitor for stress ulcer prophylaxis in critically ill patients. Crit. Care Med. 42, 809-815 (2014).

114. Freedberg, D. E. \& Abrams, J. A. Does confounding explain the association between PPIs and Clostridium difficile-related diarrhea? Am. J. Gastroenterol. 108, 278-279 (2013).

115. Barkun, A. N., Adam, V., Martel, M. \& Bardou, M. Cost-effectiveness analysis: stress ulcer bleeding prophylaxis with proton pump inhibitors, $\mathrm{H} 2$ receptor antagonists. Value Health 16, 14-22 (2013).

116. ASHP Therapeutic Guidelines on Stress Ulce Prophylaxis. ASHP Commission on Therapeutics and approved by the ASHP Board of Directors on November 14 1998. Am. J. Health. Syst. Pharm. 56, 347-379 (1999).

117. Guillamondegui, O. D. et al. Practice management guidelines for stress ulcer prophylaxis [online], https://www.east.org/resources/treatmentguidelines/stress-ulcer-prophylaxis (2008).

118. Heidelbaugh, J. J. \& Inadomi, J. M. Magnitude and economic impact of inappropriate use of stress ulcer prophylaxis in non-ICU hospitalized patients. Am. J. Gastroenterol. 101, 2200-2205 (2006)

119. Thomas, L. et al. Longitudinal analysis of the costs associated with inpatient initiation and subsequent outpatient continuation of proton pump inhibitor therapy for stress ulcer prophylaxis in a large managed care organization. J. Manag. Care Pharm. 16, 122-129 (2010)

120. Devlin, J. W., Claire, K. S., Dulchavsky, S. A \& Tyburski, J. G. Impact of trauma stress ulcer prophylaxis guidelines on drug cost and frequency of major gastrointestinal bleeding. Pharmacotherapy 19, 452-460 (1999).

121. Pitimana-aree, S. et al. Implementation of a clinical practice guideline for stress ulcer prophylaxis increases appropriateness and decreases cost of care. Intensive Care Med. 24 217-223 (1998)

122. Barkun, A. N. et al. Effectiveness of disseminating consensus management recommendations for ulcer bleeding: a cluster randomized trial. CMAJ 185, 156-166 (2013)

123. Filbin, M. R. et al. The microcirculation is preserved in emergency department low-acuity sepsis patients without hypotension. Acad. Emerg. Med. 21, 154-162 (2014).

124. Shapiro, N. I. \& Angus, D. C. A review of therapeutic attempts to recruit the microcirculation in patients with sepsis. Minerva Anestesiol. 80, 225-235 (2014).

125. Karakaya, K. et al. Mitigation of indomethacininduced gastric mucosal lesions by a potent specific type $V$ phosphodiesterase inhibitor. World J. Gastroenterol. 15, 5091-5096 (2009).

126. Taldone, T., Ochiana, S. O., Patel, P. D. $\&$ Chiosis, G. Selective targeting of the stress chaperome as a therapeutic strategy. Trends Pharmacol. Sci. (2014).

127. Bulger, J. et al. Choosing wisely in adult hospita medicine: five opportunities for improved healthcare value. J. Hosp. Med. 8, 486-492 (2013)

\section{Author contributions}

M.B. researched data for the article. M.B., J.-P.Q. and A.B. contributed equally to the discussion of content, writing and, reviewing and editing of the manuscript before submission. 